\title{
Effects of small tidal volume and positive end-expiratory pressure on oxygenation in pressure-controlled ventilation-volume guaranteed mode during one-lung ventilation
}

\author{
Sung Hye Byun, So Young Lee, Jin Yong Jung \\ Department of Anesthesiology and Pain Medicine, Catholic University of Daegu School of Medicine, Daegu, Korea
}

\begin{abstract}
Background: The purpose of this study was to investigate whether tidal volume (TV) of $8 \mathrm{~mL} / \mathrm{kg}$ without positive end-expiratory pressure (PEEP) and TV of $6 \mathrm{~mL} / \mathrm{kg}$ with or without PEEP in pressure-controlled ventilation-volume guaranteed (PCV-VG) mode can maintain arterial oxygenation and decrease inspiratory airway pressure effectively during one-lung ventilation (OLV).

Methods: The study enrolled 27 patients undergoing thoracic surgery. All patients were ventilated with PCVVG mode. During OLV, patients were initially ventilated with TV $8 \mathrm{~mL} / \mathrm{kg}$ (group TV8) without PEEP. Ventilation was subsequently changed to TV $6 \mathrm{~mL} / \mathrm{kg}$ with PEEP $\left(5 \mathrm{cmH}_{2} \mathrm{O}\right.$; group TV6+PEEP) or without (group TV6) in random sequence. Peak inspiratory pressure $\left(P_{\text {peak }}\right)$, mean airway pressure $\left(P_{\text {mean }}\right)$, and arterial blood gas analysis were measured $30 \mathrm{~min}$ after changing ventilator settings. Ventilation was then changed once more to add or eliminate PEEP $\left(5 \mathrm{cmH}_{2} \mathrm{O}\right)$, while maintaining TV $6 \mathrm{~mL} / \mathrm{kg}$. Thirty min after changing ventilator settings, the same parameters were measured once more.

Results: The $P_{\text {peak }}$ was significantly lower in group TV6 $\left(19.3 \pm 3.3 \mathrm{cmH}_{2} \mathrm{O}\right)$ than in group TV8 $\left(21.8 \pm 3.1 \mathrm{cmH}_{2} \mathrm{O}\right)$ and group TV6+PEEP $\left(20.1 \pm 3.4 \mathrm{cmH}_{2} \mathrm{O}\right)$. $\mathrm{PaO}_{2}$ was significantly higher in group TV8 $(242.5 \pm 111.4 \mathrm{mmHg})$ than in group TV6 $(202.1 \pm 101.3 \mathrm{mmHg})(p=0.044)$. There was no significant difference in $\mathrm{PaO}_{2}$ between group TV8 and group TV6+PEEP $(226.8 \pm 121.1 \mathrm{mmHg})$. However, three patients in group TV6 were dropped from the study because $\mathrm{PaO}_{2}$ was lower than $80 \mathrm{mmHg}$ after ventilation.

Conclusion: It is postulated that TV $8 \mathrm{~mL} / \mathrm{kg}$ without PEEP or TV $6 \mathrm{~mL} / \mathrm{kg}$ with $5 \mathrm{cmH}_{2} \mathrm{O}$ PEEP in PCV-VG mode during OLV can safely maintain adequate oxygenation.
\end{abstract}

Keywords: Airway pressure; Arterial oxygenation; One-lung ventilation; Pressure-controlled ventilation-volume guaranteed

\section{INTRODUCTION}

Development of one-lung ventilation (OLV) in anesthesio-

logy has greatly influenced the development of lung surgery.

Received: April 11, 2018, Revised: May 28, 2018

Accepted: May 31, 2018

Corresponding Author: Jin Yong Jung, Department of Anesthesiology and Pain Medicine, Catholic University of Daegu School of Medicine, 33, Duryugongwon-ro 17-gil, Nam-gu, Daegu 42472, Korea

Tel: +82-53-650-4505, Fax: +82-53-650-4517

E-mail: jychung@cu.ac.kr
During OLV, respiration is achieved only with a dependent lung, and the anesthesiologist must prevent hypoxemia due to increased shunting, as well as lung injury due to increased airway pressure, in contrast with two-lung ventilation [1-4]. According to previous studies comparing oxygenation rates between different ventilator modes during OLV, improvement in oxygenation in volume-controlled ventilation (VCV) and pressure-controlled ventilation (PCV) showed moderate differences in accordance with pulmonary function. Patients who were expected to have decreased pulmonary function based on preoperative pulmonary function tests showed bet-

Copyright (C) 2018 Yeungnam University College of Medicine

This is an Open Access article distributed under the terms of the Creative Commons Attribution Non-Commercial License (http://creativecommons.org/licenses/by-nc/4.0/) which permits unrestricted non-commercial use, distribution, and reproduction in any medium, provided the original work is properly cited. 
ter oxygenation with PCV, compared to that with VCV [5]. In patients with normal pulmonary function, there was no difference between VCV and PCV [6]. In studies comparing VCV with pressure-controlled ventilation-volume-guaranteed (PCV-VG), PCV-VG showed better oxygenation during OLV $[7,8]$.

In order to prevent lung injury during OLV, a protective ventilation strategy has been widely used, i.e., by lowering tidal volume and applying positive end-expiratory pressure (PEEP), which reduces lung injury while maintaining oxygenation $[1,2,9]$.

The primary goal of this study was to investigate whether a decrease in tidal volume of $6 \mathrm{~mL} / \mathrm{kg}$ with or without $5 \mathrm{cmH}_{2} \mathrm{O}$ PEEP would be enough to prevent lung barotrauma by reducing inspiratory airway pressure, while maintaining appropriate oxygenation during OLV using PCV-VG, which has the merits of PCV and the tidal volume-designating characteristic of VCV.

\section{MATERIALS AND METHODS}

The study proceeded with approval from the institutional review board of our hospital. The study enrolled 27 subjects who were classified as American Society of Anesthesiologists physical status 1 or 2 and scheduled for pulmonary surgery under OLV (Table 1). All subjects provided written informed consent before surgery. Patients scheduled for pneumonectomy were excluded. All patients received pulmonary function tests preoperatively. Subjects with forced vital capacity (FVC) lower than $70 \%$ of predicted value or those with forced expiratory volume at 1 second (FEV1) lower than $70 \%$ of predicted value were excluded. Patients with previous lung surgery or heart disease were also excluded.

All subjects were given an intramuscular injection of glycopyrrolate $0.2 \mathrm{mg}$ before entering the operating room as premedication. In the operating room, the electrocardiogram, pulse oximeter, non-invasive blood pressure, and bispectral index were monitored. Anesthesia was induced with $4 \mu \mathrm{g} / \mathrm{mL}$ of propofol and $4 \mathrm{ng} / \mathrm{mL}$ of remifentanil, using target controlled infusion (TCI). For intubation, 100\% oxygen was administrated via mask. After loss of consciousness, $1 \mathrm{mg} / \mathrm{kg}$ rocuronium was injected for muscle relaxation. After checking muscle relaxation, patients were intubated with a left-side double-lumen endotracheal tube (DLT, Silbroncho ${ }^{\circledR}$, Fuji System
Corp, Tokyo, Japan). The position of the DLT was checked by auscultation, followed by fiberoptic bronchoscopy (FOB) for confirmation. After these procedures, a 20-G catheter was installed for perioperative blood pressure monitoring and blood collection for arterial blood gas analysis (ABGA). A central venous catheter was inserted in the subclavian vein, on the ipsilateral side of the operation site. Anesthesia maintenance was achieved using $6 \mathrm{~L} / \mathrm{min} 100 \%$ oxygen, propofol, and remifentanil TCI. One hour after induction, vecuronium 0.08 $\mathrm{mg} / \mathrm{kg} / \mathrm{h}$ was additionally injected for muscle relaxation.

The location of the DLT was examined again with FOB after the patient was placed in lateral decubitus position. All patients underwent surgery using the same anesthetic equipment (Avance, GE Healthcare, Wauwatosa, WI, USA), using PCV-VG as ventilation mode. After induction, tidal volumes were $8-10 \mathrm{~mL} / \mathrm{kg}$ during two-lung ventilation. During OLV, patients were initially placed on TV $8 \mathrm{~mL} / \mathrm{kg}$ (group TV8) without PEEP. Ventilation was subsequently changed to TV $6 \mathrm{~mL} / \mathrm{kg}$ with PEEP $\left(5 \mathrm{cmH}_{2} \mathrm{O}\right.$; group TV6+PEEP) or without (group TV6), in random sequence. Peak airway pressure $\left(\mathrm{P}_{\text {peak }}\right)$, mean airway pressure $\left(\mathrm{P}_{\text {mean }}\right)$, exhaled tidal volume $\left(\mathrm{TV}_{\mathrm{E}}\right)$, peripheral oxygen saturation $\left(\mathrm{SpO}_{2}\right)$, end-tidal $\mathrm{CO}_{2}$ $\left(\mathrm{ETCO}_{2}\right)$, and $\mathrm{ABGA}$ were measured and examined just before OLV and 30 min after each mode of OLV was applied. Ventilation was changed once more to add or eliminate PEEP $\left(5 \mathrm{cmH}_{2} \mathrm{O}\right)$, while maintaining TV $6 \mathrm{~mL} / \mathrm{kg}$. Thirty min after changing ventilator settings, the same parameters were measured once more (Fig. 1). PCV-VG mode was used under 40 $\mathrm{cmH}_{2} \mathrm{O}$ of maximum airway pressure $\left(\mathrm{P}_{\max }\right)$, I:E ratio of $1: 2$, and the minimal time to reach target airway pressure was set as $5 \mathrm{~s}$. Respiratory rates during anesthesia were set equally for all patients at 12 times per min. When $\mathrm{SpO}_{2}$ levels were below $90 \%$, or when arterial partial pressure of oxygen $\left(\mathrm{PaO}_{2}\right)$ was below $80 \mathrm{mmHg}$ in ABGA, subjects were discontinued from this study and hypoxia was corrected by tidal volume elevation, relocation of DLT, or two-lung ventilation, if needed.

Sample size was calculated as 24 , with $80 \%$ power and 0.05 statistical significance, using the average and standard deviation of established values [5,9], according to all three ventilation methods. Assuming a 10\% drop-out rate, 27 subjects were included in the study. Each mode of ventilation was statistically assessed using SPSS for Windows, version 17.0 (SPSS, Chicago, IL, USA) and repeated measures analysis 


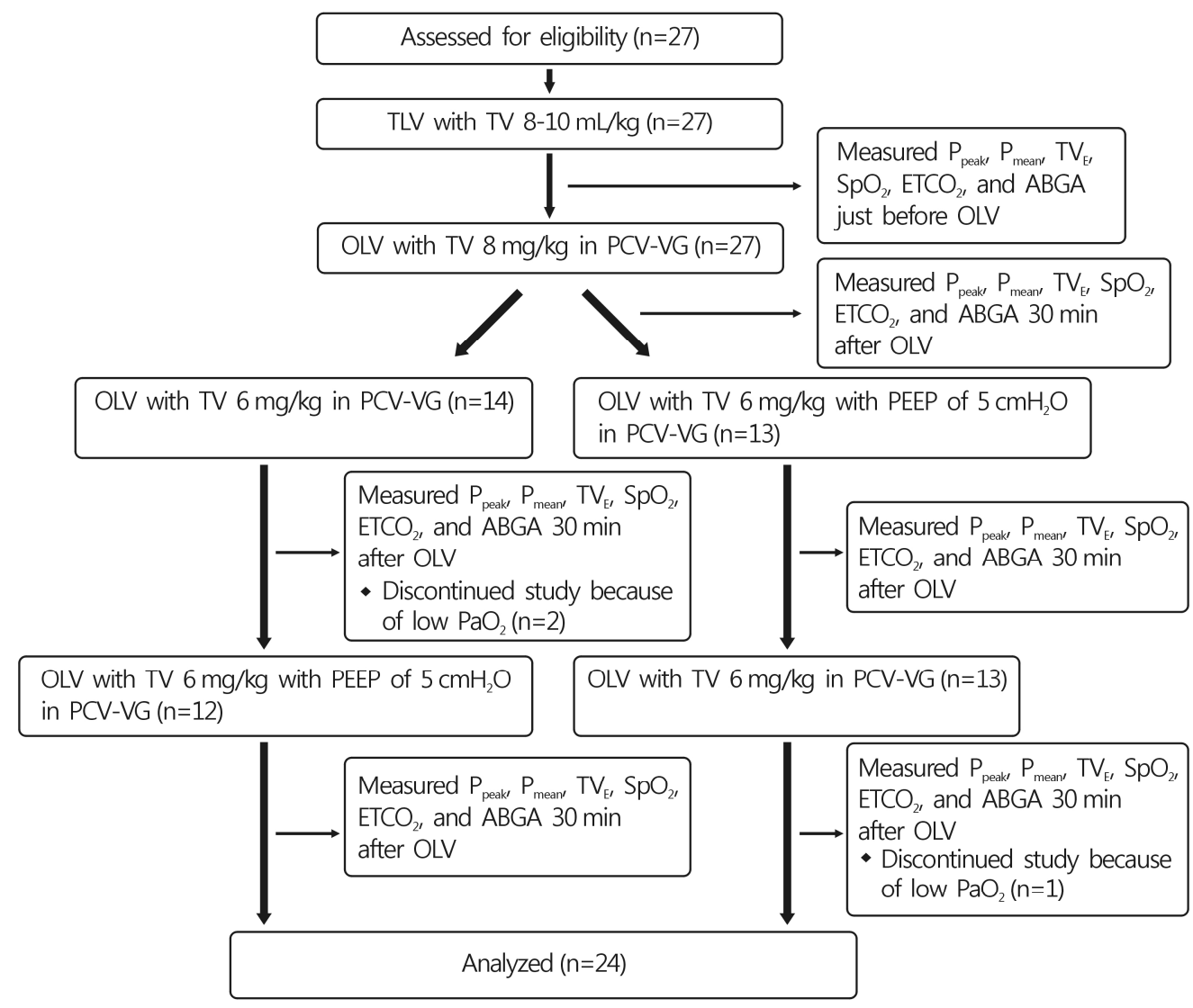

Fig. 1. Consort diagram. TLV, supine two lung ventilation; TV, tidal volume; OLV, one-lung ventilation; $\mathrm{P}_{\text {peak, }}$, peak inspiratory pressure; $\mathrm{P}_{\text {mean }}$, mean inspiratory pressure; $\mathrm{TV}_{\mathrm{E}}$, exhaled tidal volume; $\mathrm{SpO}_{2}$, peripheral oxygen saturation; $\mathrm{EtCO}_{2}$, end-tidal $\mathrm{CO}_{2} ; \mathrm{ABGA}$, arterial blood gas analysis; OLV, one-lung ventilation; PCV-VG, pressure-controlled ventilation-volume-guaranteed; PEEP, positive end expiratory pressure; $\mathrm{PaO}_{2}$, arterial oxygen pressure.

of variance. All measured values were presented as averages and standard deviations, and $p$-values $<0.05$ were considered to indicate statistical significance.

\section{RESULTS}

Of the 27 patients, three dropped out and the study was conducted statistically on the remaining 24 subjects. In these three patients, arterial oxygen partial pressure after $30 \mathrm{~min}$ of respiration with tidal volume of $6 \mathrm{~mL} / \mathrm{kg}$ on ABGA was $60.8,70.2$, and $71.8 \mathrm{mmHg}$, respectively. Although the peripheral oxygen saturation did not fall below 90\%, tidal volume was increased after interrupting the study.

Among 24 patients, 16 (males, $n=16 / 18$ ) had a past smoking history and two $(n=2 / 16)$ had both smoking and tuberculosis histories. No female patients $(\mathrm{n}=6)$ had a history of smo- king or tuberculosis (Table 1).

The $\mathrm{P}_{\text {peak }}$ values were significantly higher in the TV8 group $\left(21.8 \pm 3.1 \mathrm{cmH}_{2} \mathrm{O}\right)$ compared to the TV6 $\left(19.3 \pm 3.3 \mathrm{cmH}_{2} \mathrm{O}\right)$ and TV6+PEEP $\left(20.1 \pm 3.4 \mathrm{cmH}_{2} \mathrm{O}\right)$ groups $(p<0.002)$. The $\mathrm{P}_{\text {mean }}$ values were significantly higher in the TV6+PEEP group $\left(10.7 \pm 1.4 \mathrm{cmH}_{2} \mathrm{O}\right)$ compared to those in the other groups $(p=0.000)$. The TVE values were significantly higher in the TV8 group $(464.2 \pm 93.0 \mathrm{~mL})$, but there was no statistically significant difference between TV6 $(363.2 \pm 69.3 \mathrm{~mL})$ and TV6+PEEP $(359.6 \pm 74.7 \mathrm{~mL})$. The $\mathrm{ETCO}_{2}$ values were significantly lower in the TV8 group $(30.6 \pm 4.2 \mathrm{mmHg})$ compared to those in the other groups ( $p=0.003)$, but there were no significant differences between TV6 $(32.8 \pm 4.8 \mathrm{mmHg})$ and TV6+PEEP $(33.1 \pm 4.7 \mathrm{mmHg})(p>0.05)$ (Table 2).

The arterial oxygen partial pressure was significantly higher in TV8 group $(242.5 \pm 111.4 \mathrm{mmHg})$ than in TV6 group 
$(202.1 \pm 101.3 \mathrm{mmHg})(p=0.044)$. There was no significant difference between TV8 and TV6+PEEP groups (226.8 \pm 121.1

Table 1. Demographic variables

\begin{tabular}{lc}
\hline Age $(\mathrm{yr})$ & $66.0 \pm 9.9$ \\
Sex (male/female) & $18 / 6$ \\
Height $(\mathrm{cm})$ & $162.5 \pm 9.1$ \\
Weight $(\mathrm{kg})$ & $63.7 \pm 10.0$ \\
$\mathrm{BMI}\left(\mathrm{kg} / \mathrm{m}^{2}\right)$ & $24.1 \pm 3.0$ \\
Smoking history (male/female) & $16 / 0$ \\
Tuberculosis history (male/female) & $2 / 0$ \\
Duration of operation (min) & $261.6 \pm 68.1$ \\
Preoperative FVC (\% of predictive) & $95.4 \pm 10.7$ \\
Preoperative FEV1 (\% of predictive) & $96.6 \pm 12.5$ \\
Diagnosis & \\
Lung cancer & 20 \\
Empyema & 2 \\
Secondary pneumothorax & 2 \\
Operation site (left/right) & $11 / 13$ \\
Surgical approach & \\
VATS & 18 \\
Open thoracotomy & 6 \\
\hline BMI, body mass index; VATS, video-assisted thoracoscopic \\
surgery.
\end{tabular}

$\mathrm{mmHg})(p>0.05)$. The arterial carbon dioxide partial pressure was significantly higher in both TV6 $(42.6 \pm 6.8 \mathrm{mmHg})$ and TV6+PEEP (43.4 $\pm 7.5 \mathrm{mmHg}$ ) groups compared to that in the TV8 $(39.3 \pm 5.7 \mathrm{mmHg})$ group ( $p=0.003,0.002)$ (Table 3$)$.

There was no difference in arterial oxygen saturation, hematocrit levels, and hemodynamic variables among the three groups ( $p>0.05$ ) (Table 3, 4).

\section{DISCUSSION}

During OLV with PCV-VG, a tidal volume of $8 \mathrm{~mL} / \mathrm{kg}$ and a tidal volume of $6 \mathrm{~mL} / \mathrm{kg}$ with PEEP of $5 \mathrm{cmH}_{2} \mathrm{O}$ could safely be applied for appropriate oxygenation. Tidal volume of 6 $\mathrm{mL} / \mathrm{kg}$ without PEEP showed the lowest maximum and average inspiratory pressure. However, about $11 \%$ of our subjects (3/27) showed hypoxemia with arterial oxygen partial pressures under $80 \mathrm{mmHg}$ at a tidal volume of $6 \mathrm{~mL} / \mathrm{kg}$ without PEEP. Therefore, the authors believe that single application of tidal volume $6 \mathrm{~mL} / \mathrm{kg}$ with PCV-VG without PEEP creates a high risk of intraoperative hypoxemia.

PCV-VG is the latest addition to respiration methods used in anesthetic machines; it calculates the patient's lung com-

Table 2. Respiratory parameters according to tidal volume and application of positive end-expiratory pressure during one-lung ventilation

\begin{tabular}{lcccc}
\hline Respiratory parameter & TLV $(\mathrm{n}=24)$ & TV8 $(\mathrm{n}=24)$ & TV6 $(\mathrm{n}=24)$ & TV6+PEEP $(\mathrm{n}=24)$ \\
\hline $\mathrm{P}_{\text {peak }}\left(\mathrm{cmH}_{2} \mathrm{O}\right)$ & $17.8 \pm 4.5$ & $21.8 \pm 3.1^{\mathrm{a})}$ & $19.3 \pm 3.3^{\mathrm{b})}$ & $20.1 \pm 3.4^{\mathrm{abb}) \mathrm{c}}$ \\
$\mathrm{P}_{\text {mean }}\left(\mathrm{cmH}_{2} \mathrm{O}\right)$ & $7.3 \pm 1.5$ & $9.4 \pm 1.3^{\mathrm{a})}$ & $8.6 \pm 1.3^{\mathrm{a}) \mathrm{b}}$ & $10.7 \pm 1.4^{\mathrm{abb}) \mathrm{c}}$ \\
$\mathrm{TV}_{\mathrm{E}}(\mathrm{mL})$ & $508.8 \pm 92.6$ & $464.2 \pm 93.0^{\mathrm{a}}$ & $\left.363.2 \pm 69.3^{\mathrm{ab}}\right)$ & $359.6 \pm 74.7^{\mathrm{ab})}$ \\
$\mathrm{SpO}_{2}(\%)$ & $99.7 \pm 0.6$ & $99.0 \pm 1.7^{\mathrm{a})}$ & $99.1 \pm 1.3^{\mathrm{a})}$ & $99.5 \pm 1.1$ \\
$\mathrm{EtCO}_{2}(\mathrm{mmHg})$ & $30.4 \pm 4.3$ & $30.6 \pm 4.2$ & $32.8 \pm 4.8^{\mathrm{a}) \mathrm{b}}$ & $33.1 \pm 4.7^{\mathrm{a}) \mathrm{b}}$ \\
\hline
\end{tabular}

Data are presented as mean \pm standard deviation.

$\mathrm{P}_{\text {peak, }}$, peak inspiratory pressure; $\mathrm{P}_{\text {mean }}$, mean inspiratory pressure; $\mathrm{TV}_{\mathrm{E}}$, exhaled tidal volume; $\mathrm{SpO}_{2}$, peripheral oxygen saturation; TLV, supine two-lung ventilation; TV8, one-lung ventilation with tidal volume $8 \mathrm{~mL} / \mathrm{kg}$; TV6, one-lung ventilation with tidal volume $6 \mathrm{~mL} / \mathrm{kg}$; PEEP, $5 \mathrm{cmH}_{2} \mathrm{O}$ positive end expiratory pressure.

a) $p<0.05$ compared with TLV, ${ }^{\text {b) }} p<0.05$ compared with TV8, ${ }^{\text {c) }} p<0.05$ compared with TV6.

Table 3. Arterial blood gas values according to tidal volume and application of positive end-expiratory pressure during one-lung ventilation

\begin{tabular}{lcccc}
\hline Arterial blood gas value & TLV $(\mathrm{n}=24)$ & TV8 $(\mathrm{n}=24)$ & TV6 $(\mathrm{n}=24)$ & TV6+PEEP $(\mathrm{n}=24)$ \\
\hline $\mathrm{PaO}_{2}(\mathrm{mmHg})$ & $444.7 \pm 115.9$ & $242.5 \pm 111.4^{\mathrm{a})}$ & $202.1 \pm 101.3^{\mathrm{a}) \mathrm{b})}$ & $226.8 \pm 121.1^{\mathrm{a})}$ \\
$\mathrm{PaCO}_{2}(\mathrm{mmHg})$ & $38.5 \pm 4.0$ & $39.3 \pm 5.7$ & $42.6 \pm 6.8^{\mathrm{a} b)}$ & $\left.43.4 \pm 7.5^{\mathrm{a}) \mathrm{b}}\right)$ \\
$\mathrm{SaO}_{2}(\%)$ & $99.8 \pm 0.1$ & $98.7 \pm 1.8^{\mathrm{a})}$ & $98.9 \pm 0.9^{\mathrm{a})}$ & $98.9 \pm 1.2^{\mathrm{a})}$ \\
$\mathrm{Hematocrit}(\%)$ & $34.0 \pm 4.0$ & $34.6 \pm 3.8$ & $34.3 \pm 3.8$ & $34.4 \pm 4.0$ \\
\hline
\end{tabular}

Data are presented as mean \pm standard deviation.

$\mathrm{PaO}_{2}$, arterial oxygen pressure; $\mathrm{PaCO}_{2}$, arterial carbon dioxide pressure; $\mathrm{SaO}_{2}$, arterial oxygen saturation; TLV, supine two lung ventilation; TV8, one-lung ventilation with tidal volume $8 \mathrm{~mL} / \mathrm{kg}$; TV6, one-lung ventilation with tidal volume $6 \mathrm{~mL} / \mathrm{kg}$; PEEP, 5 $\mathrm{cmH}_{2} \mathrm{O}$ positive end expiratory pressure.

a) $p<0.05$ compared with TLV, b) $p<0.05$ compared with TV8, ${ }^{\text {c) }} p<0.05$ compared with TV6. 
Table 4. Hemodynamic variables according to tidal volume and application of positive end-expiratory pressure during one-lung ventilation

\begin{tabular}{lcccc}
\hline Hemodynamic variable & TLV $(\mathrm{n}=24)$ & TV8 $(\mathrm{n}=24)$ & TV6 $(\mathrm{n}=24)$ & TV6+PEEP $(\mathrm{n}=24)$ \\
\hline SBP $(\mathrm{mmHg})$ & $119.8 \pm 18.5$ & $129.5 \pm 21.6$ & $129.9 \pm 19.3$ & $126.3 \pm 13.4$ \\
DBP $(\mathrm{mmHg})$ & $66.0 \pm 9.9$ & $67.4 \pm 12.8$ & $67.6 \pm 9.6$ & $65.9 \pm 9.1$ \\
Heart rate (beats/min) & $66.8 \pm 14.6$ & $67.7 \pm 14.2$ & $68.3 \pm 15.1$ & $66.7 \pm 14.3$ \\
\hline
\end{tabular}

Data are presented as mean \pm standard deviation. No significant differences were noted among the groups.

SBP, systolic blood pressure; DBP, diastolic blood pressure; TLV, supine two lung ventilation; TV8, one-lung ventilation with tidal volume $8 \mathrm{~mL} / \mathrm{kg}$; TV6, one-lung ventilation with tidal volume $6 \mathrm{~mL} / \mathrm{kg}$; PEEP, $5 \mathrm{cmH}_{2} \mathrm{O}$ positive end expiratory pressure.

pliance by initial respiration with VCV mode, followed by programmed control of tidal volumes, which are previously set [10]. Song et al. [11] reported that using PCV-VG mode increased expiratory volume compared to that using VCV mode.

In PCV mode, the tidal volume can change depending on lung compliance, leading to hypercarbia caused by decreased minute volumes. In PCV-VG mode, when compared to VCV mode, expiratory volume is increased and can be maintained, keeping the minute volume at appropriate levels. Theoretically, PCV-VG can lower airway pressure during inspiration, thus improving oxygenation by matching the $\mathrm{V} / \mathrm{Q}$ ratio of the dependent lung. Bouls and Ghobrial [7] previously reported that using tidal volumes of $8-10 \mathrm{~mL} / \mathrm{kg}$ can improve oxygenation during OLV in PCV-VG mode, compared to that in VCV mode. Moreover, Pu et al. [8] reported that using tidal volumes of $8-10 \mathrm{~mL} / \mathrm{kg}$ can improve oxygenation during OLV in PCV-VG mode. However, Song et al. [11] reported that tidal volume of $8 \mathrm{~mL} / \mathrm{kg}$ reduces peak airway pressure, but does not lead to statistically significant differences in arterial oxygen partial pressure between PCV-VG and VCV. According to previous studies, application of PCV-VG in anesthesiology is desirable. Therefore, the authors investigated the optimal tidal volume for use of PCV-VG mode, which can successfully lower the airway pressure while also improving oxygenation.

In OLV using VCV mode, a minimum tidal volume of 8 $\mathrm{mL} / \mathrm{kg}$ maintains oxygenation while not causing atelectasis [12]. Moreover, tidal volume of $9 \mathrm{~mL} / \mathrm{kg}$ or lower has not been reported to cause lung injury [13]. Kim et al. [14] reported that the probability of hypoxemia is $70 \%$ when tidal volume of $6 \mathrm{~mL} / \mathrm{kg}$ is used during OLV with VCV mode and $65 \%$ when $5 \mathrm{cmH}_{2} \mathrm{O}$ of PEEP is added to tidal volume of $6 \mathrm{~mL} / \mathrm{kg}$. These data show a much higher hypoxemia incidence compared with 5\% hypoxemia incidence when tidal volume $10 \mathrm{~mL} / \mathrm{kg}$ was used for OLV with VCV. In addition, at tidal volume of $10 \mathrm{~mL} / \mathrm{kg}$, there were no cases showing expansion pressure of up to $37 \mathrm{cmH}_{2} \mathrm{O}$, leading to the conclusion that there was no pulmonary damage. Therefore, in patients with normal lung function, high tidal volume such as $10 \mathrm{~mL} / \mathrm{kg}$ increases the arterial oxygen partial pressure, and OLV does not cause complications such as lung injury. In the present study, using tidal volume of $6 \mathrm{~mL} / \mathrm{kg}$ in PCV-VG mode caused hypoxemia in $11 \%$ of patients. Hypoxemia did not occur when using tidal volume of $8 \mathrm{~mL} / \mathrm{kg}$ or $6 \mathrm{~mL} / \mathrm{kg}$ with $5 \mathrm{cmH}_{2} \mathrm{O}$ of PEEP in PCV-VG mode, thus leading to the conclusion that both methods can be applied safely while using PCV-VG mode. In addition, it is thought that there was low risk of barotrauma in PCV-VG mode, since peak inspiratory pressures were measured at about $20 \mathrm{cmH}_{2} \mathrm{O}$ in all three groups.

The limitation of this study is the consistent application of ventilator modes, i.e., tidal volume of $8 \mathrm{~mL} / \mathrm{kg}$, followed by $6 \mathrm{~mL} / \mathrm{kg}$ with or without $5 \mathrm{cmH}_{2} \mathrm{O}$ of PEEP. In addition, the shunt ratios during lung surgery may have changed due to pulmonary artery ligation, or handling of the surgical site. As a result, the surgery itself may have influenced the arterial oxygen partial pressure. Since the authors conducted the study in the routine order noted above, the early period of OLV may have maintained better arterial oxygenation. Another limitation is that ideal body weight was not used in calculating the tidal volume. In overweight patients, the tidal volumes may have been overestimated, resulting in possible high airway pressure and causing negative influence on oxygenation. However, since our subjects' mean body mass index was approximately $24 \mathrm{~kg} / \mathrm{m}^{2}$, its effect on the study was thought to be minimal. In addition, further study on the clinical implication of low tidal volume in PCV-VG is needed because the postoperative pulmonary status was not measured in this study.

In conclusion, while using PCV-VG mode during OLV, a tidal volume of $8 \mathrm{~mL} / \mathrm{kg}$ or $6 \mathrm{~mL} / \mathrm{kg}$ with added PEEP of 
$5 \mathrm{cmH}_{2} \mathrm{O}$ is thought to be a safe method of artificial ventilation, and can reduce airway pressure while maintaining appropriate oxygenation.

\section{CONFLICT OF INTEREST}

No potential conflict of interest relevant to this article were re ported.

\section{ORCID}

Sung Hye Byun, https://orcid.org/0000-0002-9287-5087

Jin Yong Jung, https://orcid.org/0000-0003-2662-3540

\section{REFERENCES}

1. Yun du G, Han JI, Kim DY, Kim JH, Kim YJ, Chung RK. Is small tidal volume with low positive end expiratory pressure during one-lung ventilation an effective ventilation method for endoscopic thoracic surgery? Korean J Anesthesiol 2014;67: 329-33.

2. Kim H. Protective strategies for one-lung ventilation. Korean J Anesthesiol 2014;67:233-4.

3. Jung JD, Kim SH, Yu BS, Kim HJ. Effects of a preemptive alveolar recruitment strategy on arterial oxygenation during one-lung ventilation with different tidal volumes in patients with normal pulmonary function test. Korean J Anesthesiol 2014;67:96-102.

4. Lee W, Lee JY, Choi DN, Shin CM, Cho K, Kim MH, et al. Airway dimensions and margin of safety with the left-sided double-lumen tube in patients of a short stature. Anesth Pain Med 2015;10:110-7.

5. Tuğrul M, Camci E, Karadeniz H, Sentürk M, Pembeci K, Akpir K. Comparison of volume controlled with pressure controlled ventilation during one-lung anaesthesia. Br J Anaesth 1997;79:306-10.

6. Unzueta MC, Casas JI, Moral MV. Pressure-controlled versus volume-controlled ventilation during one-lung ventilation for thoracic surgery. Anesth Analg 2007;104:1029-33.

7. Boules NS, Ghobrial HZ. Efficiency of the newly introduced ventilatory mode "pressure controlled ventilation-volume guaranteed" in thoracic surgery with one lung ventilation. Egypt J Anaesth 2011;27:113-9.

8. Pu J, Liu Z, Yang L, Wang Y, Jiang J. Applications of pressure control ventilation volume guaranteed during one-lung ventilation in thoracic surgery. Int J Clin Exp Med 2014;7:1094-8.

9. Végh T, Juhász M, Szatmári S, Enyedi A, Sessler DI, Szegedi $\mathrm{LL}$, et al. Effects of different tidal volumes for one-lung ventilation on oxygenation with open chest condition and surgical manipulation: a randomised cross-over trial. Minerva Anestesiol 2013;79:24-32.

10. Keszler M. Volume-targeted ventilation. Early Hum Dev 2006; 82:811-8.

11. Song SY, Jung JY, Cho MS, Kim JH, Ryu TH, Kim BI. Volume-controlled versus pressure-controlled ventilation-volume guaranteed mode during one-lung ventilation. Korean J Anesthesiol 2014;67:258-63.

12. Gal TJ. Con: low tidal volumes are indicated during one-lung ventilation. Anesth Analg 2006;103:271-3.

13. Fernández-Pérez ER, Sprung J, Afessa B, Warner DO, Vachon $\mathrm{CM}$, Schroeder DR, et al. Intraoperative ventilator settings and acute lung injury after elective surgery: a nested case control study. Thorax 2009;64:121-7.

14. Kim SH, Jung KT, An TH. Effects of tidal volume and PEEP on arterial blood gases and pulmonary mechanics during onelung ventilation. J Anesth 2012;26:568-73. 